\title{
La historiografía sobre las izquierdas en Chile: un campo en expansión
}

\section{Rolando Álvarez Vallejos}

Universidad de Santiago de Chile rolando.alvarez@usach.cl

Title: The historiography of the Left in Chile: A Burgeoning Field

Resumen: El presente artículo examina la evolución de la historiografia sobre las izquierdas en Chile desde el retorno a la democracia en 1990 hasta el presente. Plantea que a partir de cambios político-sociales relacionados con el contexto nacional del país, así como por otros producidos en los cuerpos docentes de las principales universidades chilenas, el campo historiográfico sobre las izquierdas ha experimentado un marcado proceso de expansión. Se examinan los principales autores y corrientes que dieron origen a las nuevas orientaciones de la historiografia de las izquierdas, surgidas durante la década de 1980 en Chile a partir de las reflexiones académicas y politicas de los cientistas sociales de la época. A partir de esto, el artículo ofrece una visión panorámica de la producción historiográfica sobre las izquierdas chilenas en las últimas tres décadas.

Palabras clave: izquierdas - historiografia - partidos politicos - sindicalismo

Abstract: The following article examines the development of the historiography of the Left in Chile, from the transition to democracy in 1990 to the present. It argues that the field has experienced a significant expansion and diversification, propelled by social and political changes within Chile and by changes in the faculty of the country's main universities. It analyzes, first, the pioneering trends and the work of those who, inspired by the political and academic debates of the 1980 s, led the scholarship in new directions. It provides, then, a panoramic view of the scholarship on the Chilean Left in the last three decades.

Keywords: left - historiography - political parties - trade unionism

Recepción: 16 de diciembre de 2018. Aceptación: 10 de enero de 2019. 
La historiografia sobre la izquierda chilena ha tenido un importante desarrollo en las últimas décadas. Hoy en día sistemáticamente se publican libros y artículos en revistas científicas de Chile y el extranjero sobre distintos aspectos de su trayectoria en el siglo XX y las primeras décadas del siglo XXI. A nivel de tesis de grado y posgrado, las nuevas generaciones de historiadores e historiadoras anuncian nuevos trabajos que alimentan una masa de producción historiográfica que está lejos de agotarse. Producto de razones históricas y politicas que afectaron al país, la historiografia de la izquierda chilena por años fue escasamente visitada, cuestión que solo en las últimas dos décadas comenzó a ser revertida. Iniciativas editoriales, como Lom Ediciones y más recientemente América en Movimiento, o proyectos como la revista Izquierdas, han dado gran visibilidad a la producción historiográfica sobre la izquierda chilena. Cada año, el programa estatal Fondecyt, el principal mecanismo de financiamiento de la investigación científica en Chile, aprueba proyectos sobre partidos de izquierda, experiencias militantes y movimientos sociales. Inclusive, investigadores chilenos han comenzado a realizar pesquisas transnacionales, realizando proyectos de estudios comparados con los casos especialmente de Argentina y Uruguay. ${ }^{1}$ Así, es posible afirmar que en la actualidad Chile vive un momento de especial desarrollo de investigaciones sobre la historia de las izquierdas.

De acuerdo a nuestra perspectiva, el desarrollo de la historiografia chilena durante el siglo XXI tiene algunas características fundamentales. En primer lugar, no conforma un programa de investigación común o tampoco se refugia en un paradigma historiográfico genérico que lo aglutine. Por el contrario, la caracteriza la fragmentación temática y epistemológica. Solo es posible detectar ciertos hilos conductores generados por algunas líneas de investigación de algunos de los más importantes historiadores chilenos. Con todo, esto no alcanza a constituir una escuela o matrices orgánicas comunes de proyectos historiográficos. Así, la historiografia de las izquierdas en Chile no escapa de la tendencia global, que vincula su quehacer al de los historiadores universitarios y a los estudiantes de posgrado. Además, los programas de investigación dependen en gran medida, de lograr financiamiento externo. El formato de la investigación en Chile, basado en proyectos individuales de 3 o 4 años de duración, tras los cuales se debe volver a concursar para obtener financiamiento, tiende a reforzar la fragmentación del quehacer de los profesionales de la historia. Evidentemente este hecho escapa de

1. Son los casos de las investigaciones que se encuentran desarrollando las historiadoras chilenas María Olga Ruiz y Tamara Vidaurrázaga. 
los límites del gremio de historiadores e historiadoras y se relaciona con aspectos epocales ligados a las formas como se lleva a cabo la investigación científica en una sociedad neoliberal como la chilena.

En segundo lugar, al igual que en el resto de América Latina, la historiografia de las izquierdas convivió con la tensión entre la historia "científica" y la "militante". Desarrollada fundamentalmente por personas que tienen gran afinidad con su objeto de estudio, la historiografia chilena sobre la izquierda ha debido recorrer un camino para diferenciar los trabajos propiamente políticos con la producción de textos acordes con el canon historiográfico "científico". En la actualidad, producto de la cada vez más acentuada profesionalización del quehacer de la disciplina, la historiografia de las izquierdas ha logrado ocupar un espacio entre los saberes reconocidos en el gremio de la historia. Por este motivo, desde 1990 hasta el presente, pasó de ser un campo marginal y políticamente incorrecto dentro del gremio de los historiadores, a ser una de las áreas más productivas y que convoca mayor interés entre los estudiantes de posgrado. Esto también se puede apreciar al evaluar las temáticas de los proyectos de posdoctorado e iniciación de Fondecyt, en donde la temática tiene una permanente presencia.

En tercer lugar, en Chile el marxismo sufrió un serio revés histórico, que no solo se expresó en la derrota política de la izquierda, sino también en distintas esferas, incluidas las ciencias sociales. Los historiadores de izquierda aglutinados en la llamada "nueva historia social", encabezada por Gabriel Salazar y conformada por Mario Garcés, Julio Pinto y María Angélica Illanes, fueron descritos por el historiador Eduardo Devés como una generación unida por "un marxismo mínimo". Es decir, aunque sin abandonar la matriz marxista, quienes serian los formadores de la generación de historiadores de la posdictadura en Chile, representaron una escuela historiográfica que durante el "invierno de la teoria" (así se denominó un seminario historiográfico realizado en Santiago a fines de la década de 1990), optó por caminos más eclécticos y por una mirada laxa ante el paradigma que ponía a la clase como centro de la problemática histórica. Por ello, en la actualidad en Chile no existe una abundante historiografia chilena desde la perspectiva de clase. Predominan, por el contrario, los enfoques de las culturas políticas, la identidad, los imaginarios, las representaciones y las subjetividades militantes. Más recientemente, han irrumpido los enfoques de género y raza, aunque todavía de manera muy tímida.

En cuarto lugar, en la actualidad la producción historiográfica sobre la izquierda chilena se encuentra viviendo un proceso de transición. Terminada la dictadura de Pinochet en 1990, durante un extenso período, el trabajo historiográfico se dedicó a reconstruir la trayectoria de este sector político, brutalmente reprimido durante ese régimen y, 
en gran medida, borrado de la historia por la predominante historiografia conservadora. Peor aún, la triunfante Concertación proclamó un discurso oficial que intentó establecer -con bastante éxito durante la década de 1990- una visión de la historia de Chile que enfatizaba los consensos y excluía del relato las luchas sociales y las formas más radicales de combate contra la dictadura, desarrollada por fuerzas de izquierda. Por ello, "contar lo que pasó" fue la primera necesidad que abordaron los historiadores preocupados por el pasado de la izquierda chilena. En buena medida, las nuevas generaciones formadas bajo el alero de estos especialistas continuaron esta tarea. Sin embargo, en la actualidad este modelo tiende a agotarse. El sindrome de la repetición de enfoques temáticos es notorio, especialmente en algunas áreas. Por lo tanto, las nuevas generaciones de historiadores, así como también los investigadores "senior", están abriéndose a nuevas perspectivas y enfoques para volver a pesquisar períodos y acontecimientos visitados en indagatorias anteriores. De esa forma, en distintos campos temáticos que engloba la "historiografia de las izquierdas" en Chile, están irrumpiendo novedades historiográficas que cada vez más dejan atrás el testimonialismo de las primeras investigaciones.

En quinto lugar, desde el retorno a la democracia la historiografia sobre la izquierda chilena ha tenido importantes continuidades respecto a la etapa previa a 1973, pero también novedades rupturistas. Por un lado, los partidos políticos siguieron siendo objeto privilegiado de las pesquisas. Destacan especialmente el Movimiento de Izquierda Revolucionaria (MIR), organización que a pesar de ser fundada en 1965, producto de ser la primera organización chilena que proclamó la lucha armada como vía para la construcción del socialismo, ha cautivado a las nuevas generaciones de historiadores. A la vez, su desaparición a comienzos de 1990, la convirtió en un objeto de estudio que tiene un comienzo y un fin claramente establecido. Por su parte, el Partido Comunista de Chile, poseedor de una larguísima trayectoria histórica, también ha sido ampliamente estudiado. No se puede decir lo mismo del Partido Socialista de Chile, que fuera fundado, entre otros, por Salvador Allende, la principal figura histórica de la izquierda chilena en el siglo XX.

Por otro lado, una de las principales novedades temáticas de la historiografia chilena sobre las izquierdas la representan las investigaciones sobre el anarquismo. ${ }^{2}$ Olvidada y vilipendiada por la primera generación de historiadores marxistas anteriores al golpe de Estado de 1973, la corriente anarquista en la actualidad cuenta con importantes trabajos,

2. Una completa revisión del desarrollo de la historiografia sobre el anarquismo en Chile la realizó Godoy (2016: 453-476). 
que han servido para hacer justicia a su papel dentro del desarrollo del movimiento popular chileno.

Por último, la historia del movimiento sindical constituye un espacio particular. En Chile a lo largo del siglo XX, el sindicalismo estuvo estrechamente vinculado a la izquierda. Sus principales dirigentes militaban en colectividades pertenecientes a este espectro político. Aunque partidos de centro como la Democracia Cristiana y el Partido Radical contaron con influencia en su interior, sin temor a equivocarse, se puede afirmar que las izquierdas fueron ampliamente hegemónicas al interior del movimiento sindical chileno. Luego del golpe de Estado del 11 de septiembre de 1973, que impuso la prolongada dictadura cívico-militar encabezada por Augusto Pinochet, la historiografia sobre el movimiento popular sufrió una severa ruptura epistemológica. La "historia del movimiento obrero", forma principal como la historiografia sobre las clases dominadas denominaba a su objeto de estudio, dio paso a una nueva concepción. En efecto, los historiadores de la corriente de la "nueva historia social" depusieron al "obrero" como único actor popular, privilegiando las indagaciones sobre el denominado "bajo pueblo" y los sectores no organizados. En este aspecto destacó especialmente el influyente programa historiográfico de Gabriel Salazar. ${ }^{3}$ Solo algunos historiadores, como Jorge Rojas Flores y Sergio Grez Toso, continuaron la indagatoria sobre los trabajadores organizados. Sin embargo, tras un largo periodo en que parecía que estos especialistas estaban solos en esta cruzada, en los últimos diez años se ha renovado el interés por la historia sindical, incluida su fase más reciente, después del retorno de la democracia en 1990. Las movilizaciones sociales de 2011 constituyeron un momento de repolitización de la sociedad chilena que, de alguna u otra manera, se ha expresado en el campo historiográfico en el interés de rescatar el enfoque de clase para analizar la sociedad chilena. De esta forma, las investigaciones sobre el movimiento sindical han recuperado interés en las nuevas generaciones de historiadores e historiadoras.

En sexto y último lugar, en la actualidad, la tendencia más genérica del campo de estudio de las izquierdas es evitar la separación radical o explícita entre historia politica e historia social. Esta dicotomía ha dado paso a la integración de las miradas, en donde también se han incluido crecientemente temáticas culturales, como las representaciones, imaginarios y construcciones de género. Así, corrientemente se investiga a los partidos politicos de izquierda en relación a sus conexiones con las organizaciones sociales y su inserción de masas. Y, al revés, se tiende a pesquisar las organizaciones de la sociedad civil, como sindicatos y

3. Al respecto, es paradigmático la introducción inicial del libro de Gabriel Salazar (1985). 
organizaciones territoriales, teniendo en cuenta el papel más o menos determinante de los partidos políticos de izquierda. Aunque algunos especialistas chilenos han planteado que estas expresiones constituirian lo que han denominado como una "nueva historia politica" (Ponce y Pérez, 2013: 453-476), nosotros preferimos denominarla una "historia político-social", en referencia explícita a que la frontera entre la historia social y la historia política se disuelve en objetos de estudio que unifican estos campos otrora tan claramente separados.

En resumen, la historiografia sobre las izquierdas disfruta de un presente saludable, con prometedoras perspectivas de futuro, porque numerosas nuevas investigaciones en desarrollo permiten abrigar esperanzas sobre el desarrollo de nuevas líneas de investigación, dispuestas a romper y repensar antiguas verdades sobre distintos tópicos.

Para comprender el actual desarrollo de la historiografia sobre las izquierdas en Chile, es necesario remontarse un par de décadas hacia el pasado. El año 1990 fue un año bisagra para comprender la historia política reciente del país. El término de la dictadura de Pinochet y el inicio del largo ciclo de gobiernos de la Concertación, fueron el marco dentro del cual se desenvolvieron las rutas de la historiografia de las izquierdas en Chile. Sin embargo, fue en la década de 1980 cuando se desarrollaron sus bases y principales soportes. En efecto, el germen de los posteriores trabajos sobre las izquierdas en Chile se relaciona con la labor del sociólogo Tomás Moulian, con la del historiador Gabriel Salazar $\mathrm{y}$, en tercer lugar, con el heterogéneo grupo de historiadores e historiadoras agrupados en la llamada generación de la "nueva historia social".

Durante 1980 Tomás Moulian, militante del MAPU Obrero-Campesino (Movimiento de Acción Popular Unitaria), editó un conjunto de textos sobre la historia política de Chile, especialmente sobre el período 1932 a 1973, con especial preocupación sobre la etapa del gobierno de la Unidad Popular (Moulian, 1983). Si bien el texto tenía una fuerte matriz sociológica, disciplina de la cual provenía Moulian, la abierta influencia gramsciana en sus trabajos lo ligaron a la reflexión historiográfica. Resumir las tesis de Moulian es una tarea que escapa a los espacios de este artículo, pero planteamos que fueron fundamentales y muy influyentes para las posteriores generaciones de historiadores, que leyeron la obra de Moulian en clave de una historia política renovada, que demostraba que los partidos de izquierda habian constituido la piedra angular del desarrollo de la democracia en Chile durante el siglo XX. En efecto, una de sus principales hipótesis señalaba que las clases dominantes chilenas sufrian de una "debilidad hegemónica", y 
"dominaban sin hegemonía". Por lo tanto, los portadores del proyecto de desarrollo económico y profundización democrática habían sido los partidos de centro pero fundamentalmente los de izquierda. Es decir, la historia de Chile en el siglo XX se había caracterizado por una derecha defensiva y antidemocrática, versus una izquierda proyectual y democratizadora. Este planteamiento, duramente rebatido por la historiadora Sofia Correa Sutil (2005), sigue siendo uno de los ejes del debate historiográfico chileno.

Por otra parte, Moulian exportó para Chile la tesis del "Estado de compromiso" que Francis Weffort acuñó para el caso brasileño. Según Moulian, entre 1938 y 1948, el sistema político chileno habría logrado un "compromiso" con los sectores en torno al proyecto industrializador y democratizador del Frente Popular. Su implementación habría sido tolerada por la derecha a cambio de paralizar la reforma agraria. Este compromiso se habría acabado con la persecución desatada contra los comunistas a partir de 1948. Esta tesis, hoy puesta en tela de juicio por diversas investigaciones, ha sido muy influyente y todavia se la puede encontrar presente en diversos trabajos sobre este período histórico.

En otro ámbito, la verdadera obsesión del programa de investigación de Tomás Moulian fue la Unidad Popular. Al respecto, escribió varios libros, algunos de ellos decisivos, en donde esparció fructíferas hipótesis de trabajo. Por ejemplo, analizó la experiencia de la UP preguntándose si esta fue una "tragedia" o un "drama", es decir, si estaba condenada de antemano a ser derrotada o si tuvo alguna posibilidad de evitar el golpe de Estado (Moulian, 1993). En su señero trabajo junto a Manuel Antonio Garretón, entregó lúcidos aportes para responder a este aserto (Garretón y Moulian, 1983). Con respecto a la izquierda, resaltó la paradoja entre la heterodoxia de la "vía chilena al socialismo" -que se planteaba sustituir al capitalismo sin mediar una guerra civil- versus su incapacidad teórica para pensar cómo sería la sociedad poscapitalista. (Moulian, 2005). Por último, a pesar de que la óptica de algunos de sus trabajos era fuertemente tributaria de los enfoques politológicos del libro de Arturo Valenzuela El quiebre de la democracia en Chile (Moulian, 2005), Tomás Moulian fue precursor de las perspectivas más culturales sobre el período. Su texto sobre "los campos culturales" de Chile en la década de 1960 y la dimensión de "fiesta" de la Unidad Popular (Moulian, 1993) dio origen a dos influyentes libros colectivos sobre la Unidad Popular (Pinto, 2005 y 2014). Ratificando la importancia de su influencia politica y académica, Tomás Moulian publicó en 1997 un ensayo -convertido en un inusitado éxito editorial- que desmontaba desde un punto de vista de izquierda el exitismo de los gobiernos concertacionistas. Este libro fue y sigue siendo muy gravitante para quienes se dedican a investigar la dictadura militar y la posdictadura chilena, entregando claves inter- 
pretativas todavía vigentes para evaluar el desguace ideológico y político de un sector de la izquierda chilena, que adoptó en la práctica y en el discurso el legado neoliberal de Pinochet.

De esta manera, la influencia de Moulian se reflejó en la influencia de muchas de sus hipótesis sobre la historia política chilena en el siglo XX y el papel de las fuerzas de izquierda dentro de ese marco general. Su importancia radicó, por lo tanto, en entregar un lugar a la izquierda chilena dentro de la historia política del país. En una etapa de dictadura e imposición de las tesis historiográficas conservadoras, como las representadas por Gonzalo Vial Correa, la obra de Moulian fue recibida como un balón de oxígeno para quienes buscaban una reflexión historiográfica alternativa. ${ }^{4}$ Con todo, sus textos estaban lejos de ser obras definitivas y su opción cercana a la politología hizo notoria la ausencia de los actores sociales, de gran influencia en el desarrollo de la izquierda chilena.

Por su parte, Gabriel Salazar es uno de los historiadores más importantes que ha dado Chile. A mediados de 1985 publica en Chile su obra capital, titulada Peones, labradores y proletarios, la que le aseguró un lugar como primus inter pares de su generación. Pocos años más tarde publicó un nuevo texto, con lo que completó una visión general sobre la historia de Chile (Salazar, 1990). Sus tesis dieron origen a una perspectiva historiográfica de izquierdas, pero crítica de las organizaciones políticas y sindicales. Para decirlo en una apretada sintesis, Salazar plantea que el "bajo pueblo" chileno, desde los tiempos de la colonia hasta la actualidad, ha tenido capacidad de organización, deliberación y desarrollo de proyectos sociales-populares de manera autónoma al Estado, el que siempre ha reprimido esta "deliberación autonómica de los pueblos". En este esquema, el papel histórico de los partidos políticos de izquierda (y también del movimiento sindical) habría sido violentar la autonomía popular, al conectar sus proyectos emancipatorios a la participación en esferas estatales, como el parlamento y gobiernos. En el fondo, los partidos de izquierda fueron, según Salazar (1994), un factor más para impedir el desarrollo del proyecto popular autónomo.

Este planteamiento se popularizó ampliamente entre los jóvenes estudiantes de historia. Los textos de Salazar fueron leídos no solo como buenos libros de historia, sino como una fórmula política y teórica para reconstruir el tejido social-popular después de la derrota histórica que sufrió la "izquierda partidista" en 1973 y durante el ciclo de las protestas contra Pinochet. La incapacidad de derrocarlo y la integración de un

4. Gonzalo Vial Correa, que fue Ministro de Educación de Pinochet, es autor de una voluminosa historia de Chile en seis tomos, cuyos planteamientos fueron profusamente divulgados en textos escolares y otros de distribución masiva (Vial Correa, 1981). $\mathrm{El}$ resto de los volúmenes fueron publicados en los años siguientes. 
segmento importante de las fuerzas de izquierdas en el diseño de transición pactada de dictadura a democracia, parecía dar la razón a Salazar. Así, se desarrollaron numerosas tesis de grado sobre el movimiento de los pobres de la ciudad ("pobladores") y organizaciones representativas del "poder popular" (ajenas y/o alternativas al Estado), inspiradas en la obra de Salazar. Para decirlo de otra manera, fue una historiografia de izquierdas pero que negaba el papel de los partidos políticos en el proceso de construcción de una alternativa al orden dominante. Desde nuestra perspectiva, aunque de manera crítica, los planteamientos de Salazar permitieron seguir pensando en la importancia y el potencial histórico de las organizaciones sociales populares. En un periodo histórico, como la década de 1990 en Chile, en donde la euforia neoliberal popularizaba las tesis del fin de la historia, la obra de Salazar representó la existencia de una alternativa concreta de pensar la historia de Chile "desde abajo".

Por último, el tercer soporte en torno al cual se desarrollaria la historiografia sobre las izquierdas en Chile fue la "nueva historia social". Es necesario advertir que esta corriente historiográfica no debe ser considerada homogéneamente. Sus principales representantes tienen notables diferencias entre sí. Julio Pinto Vallejos representó más una línea de continuidad que de ruptura con la generación marxista anterior a 1973 que investigó los orígenes del movimiento obrero (Pinto, 1998, 2007 y 2013; Pinto y Valdivia, 2001). Mientras tanto, María Angélica Illanes fue muy receptiva a la crítica posmoderna a las ciencias sociales, incorporando nociones deconstructivas y biopoliticas en algunas de sus obras (Illanes, 2002, 2004, 2007 y 2012). Por su parte, Mario Garcés (2002), que sería el principal historiador del movimiento de los "pobladores" en Chile y promotor de la historia oral en el país, se mostraba mucho más cercano a las tesis de Gabriel Salazar. Con todo, desde nuestro punto de vista, el aporte de los trabajos de Pinto, Illanes y Garcés radicó en el desarrollo de una historiografia que se autodefinía como "social" (en el sentido de opuesta a la historia política tradicional, aquella de los grandes personajes y batallas), pero que incluía en ella a los partidos y militantes de izquierda. Como decíamos más arriba, esto se explica por la estrechísima vinculación entre los partidos políticos de izquierda y el origen y desarrollo de organizaciones sociales como sindicatos, comités de sin casa o centros culturales de todo tipo. En otras palabras, sin haberlo tematizado, era una historia social con partidos politicos incluidos.

Como ya dijimos, Chile recuperó la democracia en 1990, pero el proceso de "despinochetizar" la institucionalidad fue una tarea prolongada y según muchos sectores políticos y académicos, aún hoy día no se termina. En el caso de la historia, recién en 1992 se reabre la formación de esa carrera en la Universidad de Santiago de Chile. Durante esa década los historiadores de izquierda fueron incorporándose, poco a poco, a 
diversas universidades públicas, las que todavía estaban dominadas por sectores conservadores. Por eso, el clima de "consensos" con la derecha, la vigencia del protagonismo político de Pinochet -quien continuó siendo Comandante en Jefe del ejército hasta 1998- y las propias políticas de los gobiernos de los presidentes Aylwin y Frei, obsesionados con "olvidar el pasado y mirar al futuro", ralentizaron los procesos de desarrollo de la historiografia de las izquierdas. Pero en octubre de 1998 Pinochet fue detenido en Londres acusado de crimenes de lesa humanidad, desatando un fuerte reclamo social por la memoria y la historia. Así, en 1999 un grupo de historiadores, encabezados por Sergio Grez, Gabriel Salazar, Mario Garcés, Julio Pinto, María Angélica Illanes y Verónica Valdivia, entre otros y otras, redactaron un Manifiesto de historiadores, para responder a las visiones históricas defendidas por Pinochet y Gonzalo Vial Correa (Grez y Salazar, 1999). En breves páginas, articularon una visión alternativa de la historia de Chile, especialmente explicando las razones del golpe de Estado de 1973. La iniciativa despertó un río de debates y comentarios, posicionando, después de décadas, a la historia (como disciplina), como una cuestión de interés nacional.

De esta manera, factores institucionales, como el ingreso de académicos de izquierda a las universidades públicas, y factores nacionales, como la coyuntura generada por la captura de Pinochet y la reflexión sobre las insuficiencias del proceso chileno de transición democrática, generaron las condiciones para el desarrollo de la historiografia sobre las izquierdas en Chile. En todo caso, como reflejo de las carencias existente en este campo, algunos de los principales textos sobre la izquierda chilena publicados durante el decenio de 1990 fueron escritos en las décadas anteriores por un cientista politico y un abogado. En efecto, en 1992 se publicó la traducción de la tesis doctoral del norteamericano Paul Drake, escrita en 1977, y también en 1992 se editó la versión en español de la obra de Julio Faúndez, chileno radicado en Estados Unidos, cuya versión original databa de 1988. Por su parte, en 1999 Lom Ediciones editó un libro colectivo a cargo de Paul Drake e Iván Jaksic (1999) sobre la última década del siglo XX en Chile, en el cual los textos referidos a los movimientos sociales y partidos políticos fueron escritos por sociólogos y cientistas políticos.

Durante la década de 2000 ocurrieron a lo menos tres hechos que fueron importantes para el desarrollo de la historiografia de las izquierdas. En primer lugar, en el año 2002 se publicó Tomando su sitio, obra clave de Mario Garcés sobre el origen y desarrollo del movimiento de pobladores hasta 1970. Combinando historia oral y un frondoso cuerpo de fuentes documentales, Garcés dio vida a un texto canónico, que ha influido de manera directa en todos los investigadores que se han centrado en las organizaciones territoriales chilenas. El posterior ingreso de Garcés a la 
Universidad de Santiago de Chile lo terminó de convertir en un referente para los estudiantes de posgrado que realizan investigaciones centradas en las experiencias populares territoriales. La perspectiva de Garcés problematiza el papel de los partidos de izquierda en su interior, pero en ningún caso los descarta al estilo más radical de Salazar. En segundo lugar, se publican en español los libros de Peter Winn (2004a) y Peter de Shazo (2007). Por razones distintas, constituyeron un fuerte aliento para el desarrollo de investigaciones sobre la izquierda chilena. En el caso de Winn, su texto, que databa de 1986, terminó de consolidar la popularidad de la historia oral (algo que el mencionado libro de Garcés ya había comenzado a hacer) $\mathrm{y}$, sobre todo, dio pie a investigaciones sobre los cordones industriales durante la Unidad Popular. Su tesis sobre la existencia de una "revolución desde arriba" representada por Allende y los partidos afines a la vía pacífica al socialismo, versus una "revolución desde abajo" que escapaba del control de los partidos de izquierda, rápidamente cobró gran popularidad. Algunos la leyeron en clave "salazariana", por su crítica a los partidos. Tributarios del trabajo de Winn son muchos libros sobre la Unidad Popular, como los de Sandra Castillo (2009), Franck Gaudichaud (2016) y los de las brasileñas Elisa Campos Borges (2015) y Marcia Cury (2018), entre otros. Por su parte, el texto de Peter De Shazo (editado por primera vez en inglés en 1984) planteaba una mirada crítica a la historiografia marxista. Según él, el anarquismo y no el marxismo había sido el verdadero forjador del movimiento obrero chileno. De esta manera, se constituyó en baluarte de quienes quisieron reposicionar al anarquismo dentro de la historia de Chile. Pero, tal como había ocurrido con parte de la producción de Julio Pinto durante la década de 1990, el texto de Peter De Shazo funcionó como motivador para refutar sus polémicos planteamientos. Un caso es el libro de Jorge Navarro López (2017) que examina el papel del Partido Obrero Socialista en la segunda década del siglo XX.

El tercer hito que representó un fuerte impulso al desarrollo de la historia de las izquierdas lo simbolizó la publicación en 2005 de un célebre artículo de Sergio Grez Toso. Escrito abiertamente en clave de polémica con la tesis de Gabriel Salazar, el texto de Grez se constituyó en una especie de marco teórico de su fecundo programa de investigación. En este breve texto, Grez refutaba a Gabriel Salazar y reivindicaba como un aspecto indispensable la incorporación de la dimensión política para reconstruir la historia del mundo popular. Para ello, confrontaba su monumental trabajo sobre las organizaciones mutualistas del siglo XIX (Grez, 1997) con Peones, labradores y proletarios de Salazar. Este texto puede ser considerado como el anuncio de su trilogía que examina distintas vías de politización del movimiento popular durante las primeras décadas del siglo XX (Grez, 2007, 2011 y 2016). Su ingreso 
como profesor de jornada completa en el Departamento de Historia de la Universidad de Chile facilitó la difusión de la influencia historiográfica de Grez. Dirigiendo numerosas tesis de grado y posgrado, la óptica de una historia social con la política incluida ganó adeptos.

\section{III}

En base a estas influencias fragmentadas y dispersas, a partir de la década de 2000 hasta la actualidad, un torrente continuo de trabajos ha alimentado la producción historiográfica chilena sobre las izquierdas. Esta se ha concentrado sobre todo en algunos partidos políticos, fundamentalmente el MIR y el Partido Comunista (y su antecesor directo, el POS) y en menor medida el MAPU y mucho menos el Partido Socialista. Asimismo, ya hemos hablado sobre la recuperación de la visibilidad historiográfica del movimiento sindical y del anarquismo. Por último, las organizaciones territoriales constituyen otro foco de interés. En todo caso, tampoco han estado ausente evaluaciones de conjunto sobre la trayectoria de las izquierdas en algunas coyunturas históricas cruciales (Casals, 2010). Bajo el riesgo de cometer injusticias flagrantes por omitir autores y textos importantes, esbozaremos a continuación una breve panorámica sobre la evolución más reciente de la historiografia de las izquierdas en Chile.

En el caso del Partido Comunista, es posible diseccionar las investigaciones en varias aristas. Por un lado, existe una contundente producción bibliográfica sobre el Partido Obrero Socialista y los primeros años como PC. Destacan los mencionados trabajos de Sergio Grez como también los de Julio Pinto, que se caracterizan por ser un enfoque proveniente de la historia social, pero que se alejan del modelo "antipolítico" de Gabriel Salazar. También debe mencionarse los textos de Jorge Rojas Flores (1986, 1993 y 2018) en los que combina la trayectoria de la organización comunista de la mano de su inserción social de masas, tanto en el movimiento sindical como las organizaciones territoriales. Unido al importante libro del fallecido Jaime Massardo (2008) sobre el imaginario político de Luis Emilio Recabarren, hoy constituyen el grupo de historiadores de larga trayectoria dedicados al comunismo. Desde perspectivas distintas, el mencionado Jorge Navarro López, Nicolás Acevedo (2017) y la joven historiadora Ximena Urtubia representan a la generación de recambio. El primero ha enfatizado la dimensión cultural del activismo socialista-comunista. Por su parte, Acevedo es autor de un señero libro sobre el papel del PC en el proceso de politización campesina en las décadas de 1930 y 1940. Por último, Urtubia (2015) ha explorado las características de la subjetivación militante de la primera generación de comunistas. 
Otra vertiente de investigación del comunismo la representa la dupla compuesta por Olga Ulianova y Alfredo Riquelme. Ambos editaron tres gruesos volúmenes llamados Chile en los archivos soviéticos, que tonificaron de manera fundamental la historiografia de las izquierdas en Chile (Ulianova y Riquelme, 2005, 2009 y 2017). En estos y otros textos, la fallecida historiadora ruso-chilena desarrolló un programa de investigación consistente en examinar la dimensión internacional de la historia del comunismo chileno. Alfredo Riquelme (2009) realizó una importante monografia sobre la historia reciente del comunismo chileno, examinando como sus matrices ideológicas, en el contexto del declive del socialismo real en el mundo, marcaron su suerte durante las décadas de 1980 y 1990. En esta línea, el historiador italiano Alessandro Santoni (2011), quien investigó de manera comparada el PC italiano con el chileno, también desarrolló una mirada historiográfica basada en las conexiones transnacionales de la experiencia comunista.

Por nuestra parte, hemos examinado la historia del PC desde la perspectiva de la cultura politica, la subjetividad militante, sus conexiones con el movimiento sindical y territorial (Álvarez, 2003, 2011 y 2019). Estos trabajos forman parte del importante número de textos que se han preguntado sobre el giro armado de los comunistas durante la década de 1980, como los de los historiadores Viviana Bravo (2010), Luis Rojas Núñez (2011 y 2018) y Claudio Pérez Silva (2012). Por su parte, el historiador Manuel Loyola ha explorado en diversos tópicos de la historia del comunismo chileno, como el pensamiento de Recabarren, el papel de las juventudes comunistas, algunas disidencias y sus proyectos editoriales. Además, ha encabezado varios textos colectivos sobre la historia comunista (Loyola y Rojas, 2000; Ulianova, Loyola y Álvarez, 2012; Álvarez y Loyola, 2014). Este mezquino recuento no hace justicia con diversos historiadores e historiadoras que han abordado episodios de la historia del PC, como Augusto Samaniego y Hernán Venegas (Álvarez, Samaniego y Venegas, 2008). Además, son muy numerosas las tesis de grado y de maestría que han abordado diversos aspectos de la trayectoria comunista, que investigan materias escasamente analizadas en los trabajos citados más arriba, como el papel de las mujeres, la perspectiva de género y la vida privada. En general, es posible concluir que en el caso del PC, todavía quedan muchísimos aspectos por investigar.

Por su parte, el atractivo generado por la breve pero intensa existencia del MIR sigue siendo irresistible para las antiguas y nuevas generaciones de historiadores chilenos. Entre los primeros, destacan los textos de Julio Pinto Vallejos (en Valdivia et al., 2006, y Valdivia et al., 2008), quien además junto a Mario Garcés y otros editaron un libro con documentos para la historia de la organización de la bandera rojinegra (Naranjo et al., 2004). Una versión centrada sobre todo en la organi- 
zación interna del partido, pero que aporta una visión de conjunto de su historia, la constituyen los libros de Carlos Sandoval Ambiado (por ejemplo, Sandoval, 2004). Igor Goicovic (2012 y 2016) también entregó un breve texto que sintetiza la historia de esa colectividad, así como otro que profundiza en diversos aspectos de su trayectoria. Como todos los autores mencionados tuvieron una relación más o menos estrecha con el MIR, el texto de la historiadora griega Eugenia Palieraki (2014) constituyó una mirada "desde fuera" que causó polémica entre los especialistas del MIR. Desde su perspectiva, este no puede ser considerado "la nueva izquierda" chilena, pues la cultura politica de sus fundadores estaba profundamente anclada en las tradiciones de la "izquierda histórica". Por su parte, Tamara Vidaurrázaga (2006) y Olga Ruiz (2018) han abordado la dimensión de género y las subjetividades militantes de los integrantes del MIR. En todo caso, no se termina de comprender la magnitud de la producción historiográfica sobre esta organización sin mencionar a la editorial Escaparate y su colección "Rojo y Negro". A la fecha, cuenta con casi 20 libros que abordan distintas dimensiones de la historia mirista, a saber, desde la memoria militante, la teorización de su política militar, enfoques sobre su identidad política, experiencias de lucha armada y miliciana, su inserción en el movimiento poblacional, entre otros. Por estos motivos, en Chile constituye un lugar común afirmar que el MIR es el partido que ha convocado más investigaciones en nuestro país. En este sentido, el desafio para los inagotables interesados en examinar su trayectoria histórica será cuestionar hipótesis ampliamente aceptadas y, sobre todo, explorar nuevos enfoques y problematizaciones.

El MAPU, a pesar de ser una colectividad con una trayectoria incluso más breve que la del MIR, ha sido objeto de interés historiográfico por el carácter influyente de sus militantes. Compuesto en parte por un número importante de intelectuales universitarios provenientes de familias acomodadas, la militancia mapucista destacó por estar integrada por "hombres" y "mujeres" del poder, destacados intelectuales y hábiles lobistas y empresarios en el Chile neoliberal. Desde la perspectiva de la cultura politica y la historia intelectual, la historiadora Cristina Moyano (2009 y 2010) ha escrito dos importantes obras sobre este singular partido de la izquierda chilena. Por su parte, el politólogo Esteban Valenzuela, ex militante de la colectividad, también publicó una obra (2014) que engloba sus líneas politicas y sus conexiones con el sistema político chileno.

Una mención aparte merece el aporte de chilenas y norteamericanos que han publicados libros de historia política y social referidos a la izquierda chilena en inglés. Su impacto en el país depende fundamentalmente de la existencia de versiones traducidas. Es el caso de la Elizabeth Hutchinson (2006), que aborda la participación de las mujeres 
en los movimientos políticos a comienzos del siglo XX. Pero la barrera idiomática ha impedido que se conozcan textos importantes, como los de Katherine Hite (2000) sobre la evolución de los líderes de la izquierda chilena en la segunda mitad del siglo XX o los de Ángela Vergara (2008) y Thomas Klubock (1998), sobre los trabajadores del cobre y las politicas de género y clase en la mina El Teniente. También destaca el de Karin Rosemblatt (2000) sobre cómo el género unió a fuerzas políticas de diversos orígenes (incluidos comunistas y socialistas) en torno a una visión tradicional de familia. Muy novedoso es el texto de Jody Pavilack (2012) sobre los mineros de Lota, que pone en tela de juicio la supuesta armonía de clases promovida por la izquierda durante los primeros años del Frente Popular. Por último, cabe destacar el texto editado por Peter Winn junto a un grupo de historiadores de Estados Unidos sobre el impacto negativo que el modelo neoliberal impuesto por la dictadura tuvo sobre la clase obrera chilena (Winn, 2004b). Esperamos que no suceda con estos trabajos lo mismo que con la tesis doctoral del británico Andrew Barnard sobre el Partido Comunista. Defendida en 1977, solo 40 años después ha sido traducida al español y facilitado su conocimiento para la mayoria de la comunidad de historiadores chilenos (Barnard, 2017).

En todo caso, la composición del libro editado por José Ponce, Camilo Santibáñez y Julio Pinto (2017), sobre el accionar del movimiento sindical chileno desde 1979 hasta la actualidad, representa una sintesis generacional. De partida, los editores son parte de la nueva y vieja guardia de historiadores centrados en la historiografia social y política de Chile. Asimismo, integró un capítulo traducido al español del citado libro editado por Winn (2004b). Por último, sus principales artículos están compuestos por jóvenes historiadores que examinan la historia sindical atravesada por el papel de los partidos politicos de izquierda. Esta obra, llamada a convertirse en un referente sobre la materia, es parte de un reverdecer de libros editado en los últimos años sobre temas sindicales: el que aborda la resistencia realizada durante la dictadura y los primeros años del retorno a la democracia (Araya, 2015), la historia de la CUT, la más importante central de trabajadores en la historia de Chile (Samaniego, 2016), el fin del ciclo productivo y de acción colectiva de los trabajadores del carbón (Alfaro, 2015) o la experiencia del sector del acero (Ayala, 2016).

Esta apretada síntesis es solo una selección de la bastante más extensa gama de publicaciones que durante los últimos años se han realizado sobre la izquierda chilena. Esto demuestra que la expansión de este campo de estudio está lejos de cerrarse. La sistemática aprobación de nuevos proyectos de investigación y el desarrollo de numerosas tesis de maestría y doctorado, permiten sostener esta sentencia. El desafío 
de estas nuevas pesquisas será ir abriendo nuevas perspectivas y preguntas sobre una temática que está lejos de agotarse.

\section{Bibliografía}

Acevedo, Nicolás (2017), Un fantasma recorre el campo. Comunismo y politización campesina en Chile (1935-1948), Santiago: América en Movimiento.

Alfaro, Karen (2015), El exilio del trabajo minero en Lota (1973-2007). ¿Fin de la clase en la era neoliberal?, Concepción: Escaparate.

Álvarez Vallejos, Rolando (2003), Desde las sombras. Una historia de la clandestinidad comunista (1973-1980), Santiago: Lom.

- (2011), Arriba los pobres del mundo. Cultura e identidad politica del Partido Comunista de Chile entre democracia y dictadura, 1965-1990, Santiago: Lom.

- (2019), Hijos e hijas de la rebelión. Una historia politica y social del Partido Comunista de Chile, 1990-2000, Santiago: Lom.

Álvarez, Rolando, Augusto Samaniego y Hernán Venegas (2008), Fragmentos de una historia. El Partido Comunista en el siglo XX, Santiago: ICAL.

Álvarez, Rolando y Manuel Loyola (eds.) (2014), Un trébol de cuatro hojas. Las Juventudes Comunistas de Chile en el siglo XX, Santiago: Ariadna-América en Movimiento.

Araya, Rodrigo (2015), Organizaciones sindicales en Chile. De la resistencia a la politica de los consensos: 1983-1994, Santiago: Universidad Finis Terrae.

Ayala, Jorge (2016), Historia del movimiento sindical de Huachipato, 19702013, Concepción: Escaparate.

Barnard, Andrew (2017), El Partido Comunista de Chile, 1922-1947, Santiago: Ariadna.

Bravo, Viviana (2010), ¡Con la razón y la fuerza venceremos! La rebelión popular y la subjetividad comunista en los 80, Santiago: Ariadna.

Campos Borges, Elisa (2015), ¡Con la Unidad Popular ahora somos gobierno! A experiencia dos Cordones Industriales no Chile de Allende, Río de Janeiro: Multifoco.

Casals, Marcelo (2010), El alba de una revolución. La izquierda y el proceso de construcción estratégica de la "vía chilena al socialismo", 1956-1970, Santiago: Lom.

Castillo, Sandra (2009), Cordones Industriales. Nuevas formas de sociabilidad obrera y organización politica popular (Chile, 1970-1973), Santiago: Escaparate.

Correa, Sofia (2005), Con las riendas del poder. La derecha chilena en el siglo $X X$, Santiago: Sudamericana.

Cury, Marcia (2018), El protagonismo popular chileno. Experiencias de clase y movimientos sociales en la construcción del socialismo (1964-1973), Santiago: Lom. 
De Shazo, Peter (2007), Trabajadores urbanos y sindicatos en Chile, 19021927, Santiago: DIBAM.

Drake, Paul (1992), Socialismo y populismo en Chile, 1936-1973, Valparaíso: Instituto de Historia Universidad Católica de Valparaíso.

Drake, Paul e Iván Jaksic (1999), El modelo chileno. Democracia y desarrollo en los noventa, Santiago: Lom.

Faúndez, Julio (1992), Izquierdas y democracia en Chile, 1932-1973, Santiago: Bat.

Garcés, Mario (2002), Tomando su sitio. El movimiento de pobladores de Santiago, 1957-1970, Santiago: Lom.

Garretón, Manuel Antonio y Tomás Moulian (1983), La Unidad Popular y el conflicto politico en Chile, Santiago: CESOC.

Gaudichaud, Franck (2016), Chile ,1970-1973. Mil dias que estremecieron al mundo, Santiago: Lom.

Godoy, Eduardo (2014), La huelga del mono. Los anarquistas y las movilizaciones contra el retrato obligatorio (Valparaiso, 1913), Santiago: Quimantú.

- (2016), "Historia e historiografía del anarquismo en Chile (1980-2015)", Cuadernos de Historia, $\mathrm{n}^{\circ}$ 44, Santiago, pp. 101-137.

Goicovic, Igor (2012), Movimiento de Izquierda Revolucionaria, Concepción: Escaparate.

- (2016), Trabajadores al poder, Concepción: Escaparate.

Grez, Sergio (1998), De la "regeneración del pueblo" a la huelga general. Génesis y evolución histórica del movimiento popular en Chile (1810-1910), Santiago: DIBAM-Centro de Investigaciones Diego Barros Arana.

- (2005), "Escribir la historia de los sectores populares. ¿Con o sin la política incluida? A propósito de dos miradas de las historia social", Politica, $\mathrm{n}^{\circ}$ 44, pp. 17-31.

- (2007), Los anarquistas y el movimiento obrero. La alborada de "la Idea" en Chile, 1893-1915, Santiago: Lom.

- (2011), Historia del comunismo en Chile. La era de Recabarren (1912-1924), Santiago: Lom.

- (2016), El Partido Democrático de Chile. Auge y ocaso de una organización politica popular (1887-1927), Santiago: Lom.

Grez, Sergio y Gabriel Salazar (comps.) (1999), Manifiesto de historiadores, Santiago: Lom.

Hite, Katherine (2000), When the romanced ended. Leaders of the Chilean Left, 1968-1998, Columbia University Press.

Hutchinson, Elizabeth (2006), Labores propias de su sexo, Santiago: Lom.

Illanes, María Angélica (2002) La batalla de la memoria. Ensayos históricos de nuestro siglo. Chile, 1900-2000, Santiago: Planeta.

- (2004), Chile des-centrado. Formación socio-cultural republicana y transición capitalista. Chile, 1810-1910, Santiago: Lom.

- (2007), Cuerpo y sangre de la politica. La construcción histórica de las visitadoras sociales. Chile, 1880-1940, Santiago: Lom. 
- (2012), Nuestra historia violeta. Feminismo social y vidas de mujeres en el siglo XX: una revolución permanente, Santiago: Lom.

Klubock, Thomas Miller (1998), Contested Communities. Class, gender and politics in Chile's El Teniente Copper Mine, 1904-1951, Duke University Press.

Lagos, Manuel (2012), Los subversivos. Las maquinaciones del poder. "República" de Chile, Santiago: Quimantú.

Loyola, Manuel y Jorge Rojas (comps.) (2000), Por un rojo amanecer. Hacia una historia de los comunistas chilenos, Santiago: Valus.

Massardo, Jaime (2008), La formación del imaginario politico de Luis Emilio Recabarren, Santiago: Lom.

Moulian, Tomás (1983), Democracia y socialismo en Chile, Santiago: FLACSO.

- (1993), La forja de ilusiones: El sistema de partidos, 1932-1973, Santiago: ARCIS-FLACSO.

- (1997), Chile actual. Anatomía de un mito, Santiago: Lom.

- (2005), "La vía chilena al socialismo. Itinerario de la crisis de los discursos estratégicos de la Unidad Popular", en Julio Pinto (coord.), Cuando hicimos historia. La experiencia de la Unidad Popular, Santiago: Lom, pp. 35-56.

- (2006), Fracturas. De Pedro Aguirre Cerda a Salvador Allende (1938-1973). Santiago: Lom.

Moyano, Cristina (2009), MAPU o la seducción del poder y la juventud, Santiago: Universidad Alberto Hurtado.

- (2010), El MAPU durante la dictadura, Santiago: Universidad Alberto Hurtado.

Muñoz Cortés, Víctor (2013), Sin dios ni patrones. Historia, diversidad y conflictos del anarquismo en la región chilena (1890-1990), Santiago: Mar y Tierra.

Navarro, Jorge (2017), Revolucionarios y parlamentarios. La cultura politica del Partido Obrero Socialista (1912-1922), Santiago: Lom.

Naranjo, Pedro et al. (2004), Miguel Enríquez y el proyecto revolucionario en Chile, Santiago, Lom-CEME.

Palieraki, Eugenia (2014), “La revolución ya viene!” El MIR chileno en los sesenta, Santiago: Lom.

Pavilack, Jody (2011), Mining for the Nation. The politics of Chile's Coal Communities from the Popular Front to the Cold War, The Pennsylvania State University Press.

Pérez, Claudio (2012), "De la guerra contra Somoza a la guerra contra Pinochet. La experiencia internacionalista revolucionaria en Nicaragua y la construcción de la fuerza militar propia del Partido Comunista de Chile", en Pablo Pozzi y Claudio Pérez, Historia oral e historia politica. Izquierda y lucha armada en América Latina, 1960-1990.

Pinto, Julio (1998), Trabajos y rebeldias en la pampa salitrera. El ciclo del salitre y la reconfiguración de las identidades populares (1850-1900), Santiago: Universidad de Santiago de Chile. 
- (2005) (coord.), Cuando hicimos historia. La experiencia de la Unidad Popular, Santiago: Lom.

- (2007), Desgarros y utopías en la pampa salitrera: la consolidación de la identidad obrera en tiempos de la cuestión social (1890-1923), Santiago: Lom.

- (2013), Luis Emilio Recabarren. Una biografia histórica, Santiago: Lom.

- (ed.) (2014), Fiesta y drama. Nuevas historias de la Unidad Popular, Santiago: Lom.

Pinto, Julio y Verónica Valdivia (2001), ¿Revolución proletaria o querida chusma? Socialismo y alessandrismo en la pugna por la politización pampina (1911-1932), Santiago: Lom.

Ponce, José Ignacio y Aníbal Pérez (2013), "La revitalización de la historia politica chilena”, Polis. Revisa Latinoamericana, vol. 12, $\mathrm{n}^{\circ} 36$, Santiago, pp. 453-476.

Ponce, José et al. (2017), Trabajadores y trabajadoras. Procesos y acción sindical en el neoliberalismo chileno, 1979-2017, Santiago: América en Movimiento.

Quiroga, Patricio (2001), Compañeros. El GAP: la escolta de Allende, Santiago: Aguilar.

- (2016), La dignidad de América. El retorno histórico a Salvador Allende, Concepción: Escaparate.

Riquelme Segovia, Alfredo (2009), Rojo atardecer. El comunismo chileno entre dictadura y democracia, Santiago: Centro de investigaciones Diego Barros Arana.

Rojas, Jorge (1986), El sindicalismo y el Estado en Chile (1924-1936), Santiago: Colección Nuevo Siglo.

- (1993), La Dictadura de Ibáñez y los sindicatos (1927-1931), Santiago: Dirección de Bibliotecas, Archivos y Museos (Dibam)-Centro de Investigaciones Diego Barros Arana.

- (2018), "La lucha por la vivienda en tiempos de González Videla: Las experiencias de las poblaciones Los Nogales, Lo Zañartu y Luis Emilio Recabarren en Santiago de Chile, 1946-1947", Izquierdas, n 39, pp. 1-33.

Rojas Núñez, Luis (2011), De la rebelión popular la sublevación imaginada, Santiago: Lom.

- (2018), Carrizal. Las armas del PCCh, un recodo en el camino, Santiago: Lom.

Rosemblatt, Karin (2000), Gendered Compromises. Political cultures \& The State in Chile, 1920-1950, The University of North Carolina Press.

Ruíz, María Olga (2018), "Muertes luminosas, vidas en la oscuridad. Heroísmo y traición en la militancia revolucionaria de los setenta en la Argentina y Chile", Izquierdas, ${ }^{\circ} 40$, pp. 202-230.

Salazar, Gabriel (1985), Peones, labradores y proletarios. Formación y crisis de la sociedad popular chilena del siglo XIX, Santiago: Sur.

- (1990), Violencia política popular en las "Grandes Alamedas". La violencia en Chile, 1947-1987 (Una perspectiva histórico popular), Santiago, Sur. 
- (1994), "Luis Emilio Recabarren y el municipio popular en Chile, 19001925”, Revista de Sociología, n 9, pp. 61-82.

Samaniego, Augusto (2016), Unidad sindical desde la base. La Central Única de Trabajadores de Chile, 1953-1973, Santiago: Ariadna.

Sandoval, Carlos (2004), Movimiento de Izquierda Revolucionaria, 1970-1973. Coyunturas, documentos y vivencias, Concepción: Escaparate.

Santoni, Alessandro (2011), El comunismo italiano y la vía chilena. Los orígenes de un mito politico, Santiago: Ril.

Ulianova, Olga y Alfredo Riquelme (2005, 2009, 2017), Chile en los archivos soviéticos, 1922-1991, 3 vols., Santiago: Lom-Centro de Investigaciones Diego Barros Arana.

Ulianova, Olga, Manuel Loyola y Rolando Álvarez (eds.) (2012), 1912-2012. El siglo de los comunistas chilenos, Santiago: IDEA-USACH.

Urtubia, Ximena (2016), Hegemonía y cultura politica en el Partido Comunista de Chile: la transformación del militante tradicional, 1924-1933, Santiago: Ariadna.

Valdés, Pedro (2018), El compromiso internacionalista. El Ejército de Liberación Nacional. Los elenos chilenos, 1966-1971. Formación e identidad, Santiago: Lom.

Valdivia, Verónica et al. (2006), Su revolución contra nuestra revolución, Santiago: Lom.

- (2008), Su revolución contra nuestra revolución, vol. II, Santiago: Lom.

Valenzuela, Esteban Teo (2014), Dios, Marx... y el MAPU, Santiago: Lom.

Vergara, Ángela (2008), Copper Workers, international bussines and domestic politics in Cold War Chile, The Pennsylvania State University Press.

Vial Correa, Gonzalo (1981), Historia de Chile, 1891-1973, Santiago: Santillana.

Vidaurrázaga, Tamara (2006), Mujeres en rojo y negro, Concepción: Escaparate.

Winn, Peter (2004a), Tejedores de la revolución. Los trabajadores de Yarur y la vía chilena al socialismo, Santiago: Lom.

- (ed.) (2004b), Victims of the Chilean Miracle. Workers and Neoliberalism in the Pinochet Era, 1973-2002, Duke University Press. 